\title{
Surgical Challenges in Posterior Cervicothoracic Junction Instrumentation
}

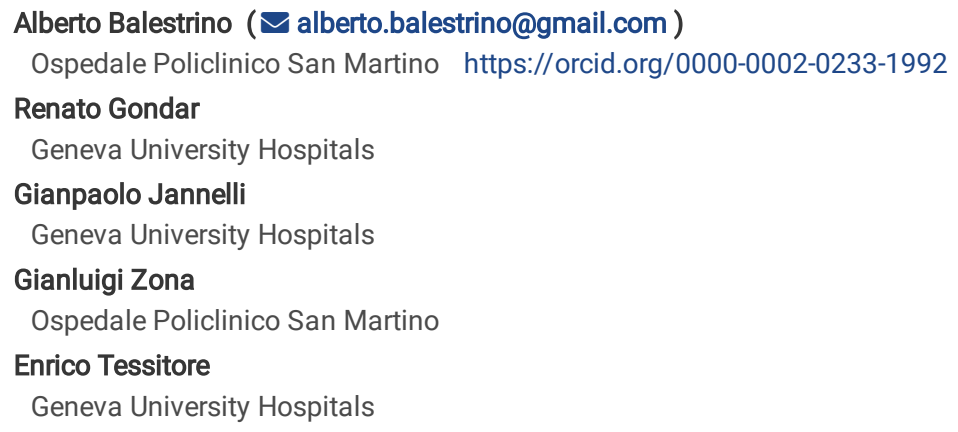

Version of Record: A version of this preprint was published at Neurosurgical Review on March 22nd, 2021. See the published version at https://doi.org/10.1007/s10143-021-01520-6. 


\section{Abstract}

Objectives: The cervicothoracic junction (CTJ) is a region of the spine submitted to significant mechanical stress. The peculiar anatomical and biomechanical characteristics make posterior surgical stabilization of this area particularly challenging. We present and discuss our surgical series highlighting the specific surgical challenges provided by this region of the spine.

Methods. We have analyzed and reported retrospective data from patients who underwent a posterior cervicothoracic instrumentation between 2011 and 2019 at the Neurosurgical Department of the Geneva University Hospitals. We have discussed C7 and Th1 instrumentation techniques, rods design, extension of constructs and spinal navigation.

Results: 36 patients were enrolled. We have preferentially used lateral mass (LM) screws in the subaxial spine, pedicle screws (PS) in C7, Th1 and upper thoracic spine. We have found no superiority of 3D navigation techniques over 2D fluoroscopy guidance in PS placement accuracy, probably due to the relatively small case series. Surgical site infection was the most frequent complication, significantly associated with tumor as diagnosis.

Conclusions: When technically feasible, PS represent the technique of choice for C7 and Th1 instrumentation although other safe techniques are available. Different rods constructs are described although significant differences in biomechanical stability still need to be clarified. Spinal navigation should be used whenever available even though 2D fluoroscopy is still a safe option. Posterior instrumentation of the CTJ is a challenging procedure but with correct surgical planning and technique it is safe and effective.

\section{Introduction}

The cervicothoracic junction (CTJ) is a transitional zone between the flexible lordotic cervical spine and the rigid kyphotic thoracic spine [5]. Thus, this area is submitted to significant mechanical stresses, the eventual disruption of its integrity may lead to critical instability.

According to the definition provided by Wang et al. [47], the CTJ involves the C7 vertebra, the Th1 vertebra, the disc between these two vertebrae and their associated ligaments.

Several approaches to the CTJ have been reported either from anterior or posterior [27]. Posterior approaches have been widely used as they warrant a solid stabilization while avoiding mediastinal structures [47]. CTJ peculiar anatomical and mechanical characteristics make this surgery a relevant challenge for spinal surgeons, who should take into account the scarce visualization of CTJ on intraoperative x-rays, the issues of difficult alignment between subaxial lateral mass (LM) screws and pedicle screws (PS) at C7 and Th1 levels, the presence of thin and very convergent pedicles, the optimal rod-construct configuration, and the cranio-caudal extension of the instrumentation. Furthermore, the relatively recent introduction of spinal navigation techniques have allowed more safety to this issue [3], possibly pushing surgeons to more ambitious strategies and leading therefore to other potential complications.

It is the objective of the present work to provide a comprehensive and critical review of the current state of the art on posterior CTJ instrumentation. We will also report data from our surgical experience and highlight some surgical challenges and controversies.

\section{Methods}

We have analyzed and reported retrospective data from patients who underwent posterior cervicothoracic instrumentation comprising $\mathrm{C7}$ and Th1 vertebrae, regardless the underlying disease, between 2011 and 2019 at the Neurosurgical Department of the Geneva University Hospitals (HUG).

Ethical approval was waived by the local Ethics Committee of Geneva CCER (IRB approval N ${ }^{\circ} 2020-01185$ ) in view of the retrospective nature of the study and all the procedures being performed were part of the routine care.

All surgical procedures were performed with a posterior standard midline open approach. All pedicle screws were inserted under radiological guidance, either 2-dimensional (2D-Fluoroscopy) or 3-dimensional (3D-Nav). 2D-Fluoroscopy was performed under C-Arm fluoroscopy guidance (Ziehm Vision FD Vario 3D, Ziehm Imaging GmbH, Nürnberg, Germany). 3D-Nav was performed using a spinal navigation system (Brainlab AG, Feldkirchen, Germany) either matched with a preoperative CT or with an intraoperative 3D acquisition before screw placement. The latter was with O-Arm (CT-Nav) (Medtronic Sofamor Danek, Inc., Memphis, Tennessee, USA) or Ziehm Vision FD Vario 3D (3D-Fluoronav) (Ziehm Imaging GmbH, Nürnberg, Germany). The O-Arm and Ziehm Vision FD Vario 3D are both surgical imaging platforms based on a flat-panel technology, while the first consists in an 0-shaped arm that requires an assisted-drive mechanism similar to mobile CT scanners, the second consists in a motorized C-shaped, highly mobile arm that resembles standard 2D-fluoroscopy units in size. Finally, using the Vectorvision Software (Brainlab AG, Feldkirchen, Germany), the virtual anatomy was compared and matched to the visible anatomical landmarks for screw navigation. A post-operative CT scan with 3D reconstructions was obtained for each patient. Pedicle screws placement accuracy was graded according to the classification from Gertzbein and Robbins (GR)[17] (Fig.1).

Only significant complications specific to the spine have been reported, such as: adjacent segment disease (ASD), defined as the pathologic process associated with disc degeneration leading to clinical symptoms, such as radiculopathy, stenosis, and instability[20]; proximal or distal junctional kyphosis (PJK or DJK) defined by a junctional sagittal Cobb angle $\geq 10^{\circ}$ and at least $10^{\circ}$ greater than the preoperative measurement[28]; proximal or distal junctional failure (PJF or DJF) defined as a structural failure that can present as vertebral body fracture, implant pull-out or breakage, and/or disruption of the posterior osteoligamentous complex[23]; cage subsidence; surgical site infection (SSI); symptomatic hematomas and neurological procedure-related complications. Need for reoperation has been also reported. Early and long-term complications were respectively defined as occurring before or after 3 months after surgery. 
The frequencies of occurrence that were observed for the various events were statistically evaluated with the Chi-square test or, if the analysis involved only two populations and two outcomes, with the Fisher's exact test. Results for continuous variables are reported as mean \pm standard deviation (SD) or range. Categorical variables are presented by absolute and relative frequencies. Two-sided $p$ values of $<0.05$ were considered as threshold for statistical significance.

A literature review has been performed in order to provide evidence-based suggestions. Given the narrative nature of our review, a full search strategy is not provided. We conducted a restricted search of articles in English language, published in PubMed/Medline until October 30, 2020 that discussed C7 and Th1 instrumentation, rods design, extension of the construct and spinal navigation in this setting. On the basis of authors' opinions, the most relevant articles for the topics of discussion were included.

\section{Results}

During the study period, 36 patients underwent posterior vertebral fixation of the CTJ (Tab.1), of these 21 were males (58.0\%) and 15 females (42.0\%). Median age was 57 years (range 18-91). Average follow-up time was 13,6 months (median 6.5 months).

Indication for surgery was a degenerative pathology in 14 cases (38.9\%), acute trauma causing primary instability in 15 cases (41.7\%) and spinal metastasis in 7 cases (19.4\%). In 19 cases (52.8\%) the primary lesion involved more than one spinal segment between subaxial spine, CTJ and upper thoracic spine below Th1. The CTJ was involved in 31 cases (86.1\%), the subaxial spine in 20 cases (55.5\%) and the upper thoracic spine in 6 cases (16.7\%) of patients. Data regarding posterior instrumentation surgery are summarized in Table 1.

The number of levels included in the extent of fixation varied greatly in our series according to the different indications and different primary lesions, ranging from a minimum of 2 levels to a maximum of 11 levels with a median of 4 involved levels $(S D=2.08)$. In 26 cases (72.2\%) a supplemental anterior support was provided to the construct.

Regarding the surgical technique, in the subaxial spine LM screws according to Magerl's technique[25] were placed in all cases except for one case in which C6 PS were placed. C7 was instrumented with PS in 23 cases (63.9\%), LM screws in 3 cases (8.3\%) and left uninstrumented in 10 cases (27.8\%). At Th1 level, PS were placed in all cases except $3(8.3 \%)$ in which the vertebra was skipped. All thoracic instrumented vertebrae below Th1 received PS. Globally we placed 110 PS in 7 and Th1, with placement accuracy summarized in Table 2.

To connect cervical and thoracic screws we have used two rods of different diameters (3.2 $\mathrm{mm}$ in subaxial, $5.5 \mathrm{~mm}$ in thoracic) linked with domino connectors in 6 cases (16.6\%), dual diameter transitional rods in 8 cases (22.3\%) and single diameter rods in 22 cases (61.1\%). Every single diameter rod was part of a cervical set (3.2mm diameter) except for one case in which a thoraco-lumbar rod (5.5mm diameter) was used. We have used small rods mostly in patients with limited extent of fusion on the upper thoracic spine, in 19 out of 22 patients $(86.4 \%)$ in which we have used small rods constructs, the lower instrumented vertebra was Th1 (14 cases) or Th2 (5 cases). In the remaining cases the lower instrumented vertebra was in 1 case Th3 and in 2 cases Th4.

With regards to $\mathrm{C} 7$ and Th1 instrumentation, 36 PS were placed in 13 patients (36.1\%) under 2D-Fluoroscopy and 70 PS were placed in 23 patients (63.9\%) under 3D-Nav. Concerning the 3D-Nav group, 3D-Fluoronav with Ziehm 3D C-Arm was used in 12 patients (52.2\%) for 37 screws and CT-Nav was used in the remaining 11 patients $(47.8 \%)$ for 33 screws.

We have found no superiority of 3D-Nav techniques compared to 2D-Fluoroscopy in PS placement accuracy either considering optimal screw placement (GR:A) versus non-optimal placement (GR: $B+C+D+E)$, and acceptable screw placement (GR: $A+B)$ versus not acceptable screw placement (GR:C+D+E) (Tab.3). By contrast, in a subgroup analysis of the different screw placement techniques, we have found a small but significant $(p<0.05)$ superiority in optimal screw placement (GR:A) of 2D-Fluoroscopy guidance and 3D-Fluoroscopy navigation compared with 0-Arm navigation (Tab.4). In the same subgroup analysis, no significant differences were found between acceptable screw placement (GR: A+B) and not acceptable screw placement (GR:C+D+E) (Tab.4).

Early postoperative complications occurred in 8 patients (22.2\%). No long-term complications occurred during the follow-up period in our series. SSI was the most frequent complication, occurring in 7 patients (19.4\%). Post-operative CSF leak was documented in 2 patients. As expected[31], SSIs was significantly associated with tumoral cases as underlying pathology $(\mathrm{p}<0.05)$. All SSI cases needed a revision surgery followed by antibiotic therapy. By contrast, the 2 cases of CSF leak were treated conservatively with complete resolution of the symptoms.

No cases of neurological deterioration after surgery were recorded.

Despite the significant biomechanical forces applied to metal constructs related to the transitional nature of the CTJ, we have observed only one PJF and no other mechanical complications, including no hardware failures during the follow-up period. The only patient who experienced PJF was a 53 years old male with type I diabetes and alcohol addiction. He underwent a circumferential C6-T1 fusion with posterior instrumentation and anterior column recontruction for an amyelic $\mathrm{C} 7$ unstable fracture. $\mathrm{C} 7$ was left uninstrumented because of significant fracture that prevented instrumentation.

\section{Discussion}

A limited number of studies that focused on instrumentation of the CTJ are available in literature, most of them being in vitro biomechanical studies. Both C7 and Th1, despite being part of cervical subaxial and thoracic spine respectively, differ from other vertebrae, thus requiring specific and tailored techniques for their instrumentation. In addition, the biomechanical stress provided by the transitional characteristics of the CTJ demands critical thinking on optimal extent of the arthrodesis area in an effort to prevent failure of instrumentation and adjacent segment diseases. Despite technical advances, instrumentation of the 
CTJ remains challenging and carries significant complication rates. We focused our attention on few specific issues and pitfalls, namely $\mathrm{C7}$ and Th1 instrumentation techniques and rods design, need for crossing CTJ in posterior constructs and role of spinal navigation.

\section{Challenges and pitfalls of C7 and Th1 instrumentation}

C7 is a transitional vertebra with unique anatomical characteristics that differs from other subaxial and upper thoracic vertebrae[11]. This peculiar anatomy resides in the gradual anatomical changes between the mobile cervical spine and the stiff thoracic spine. From C5 to Th3 pedicles increase in diameter and dimension of LM gradually decrease from C3 to C7 resulting in their gradual conversion to transverse processes[29]. Current options in C7 fixation are PS (Fig.2), LM screws (Fig.3), trans-facet screws and trans-laminar screws (Fig.4)[2].

Even though it remains challenging, PS are more feasible in C7 than in other subaxial vertebrae. PS have shown to provide the highest biomechanical stability in posterior $\mathrm{C} 7$ fixation $[13,29]$ therefore should always be considered, especially in multilevel constructs, in cases with no anterior support or in osteoporotic patients[16]. Additionally, PS should be considered in thoracic constructs ending at C7 because of the great biomechanical forces implied in these cases on the upper instrumented vertebra. The most used insertion technique, as proposed by Lee et al.[33] consists in an entry point 1.6mm lateral and $2.5 \mathrm{~mm}$ superior to the center of LM with an approximately $7^{\circ}$ cranial trajectory. In order to provide additional safety to the procedure, Clifton et al.[8] proposed a direct palpation of the pedicle with a small angled blunt dissector through a small laminotomy in order to be aware of how much medial angulation is needed in screw insertion.

In our series PS, whenever feasible, were the instrumentation technique of choice for C7, used for 23 out of 36 cases ( $63,9 \%)$. In 10 cases C7 was left uninstrumented because it was judged to be too hazardous because of the anatomical changes by the underlying pathology. We have observed no screws loosening or pull-out complications at latest follow-up. This finding is consistent with the high biomechanical stability of PS reported in literature.

LM fixation of C7, despite being more challenging than other subaxial vertebrae, represents a valuable option. Several techniques are available for LM fixation. According to the technique proposed by Roy-Camille[36] the entry point is at the center of the LM and screw trajectory has to be perpendicular to the LM cortex with a $10^{\circ}$ lateral angulation. Magerl[25] subsequently proposed a modified technique with an entry point slightly medial and cranial to the midpoint of LM and the screw trajectory parallel to the adjacent facet joint plane with a $20-30^{\circ}$ of lateral angulation. This technique resulted in higher screw strength secondary to the longer screw purchase[42] with lower rates of facet joint violation but higher risks of nerve injury[19]. More recently Riew[16] proposed a modification of the technique by setting the entry point $1 \mathrm{~mm}$ medial and $1 \mathrm{~mm}$ caudal to the midpoint of the LM with a cranial and lateral angulation of screw trajectory aiming at the upper and outer corner of the LM. This technique has been proposed with the aim of simplification of the previous techniques by making screw trajectories easier to follow avoiding the need to intraoperatively guess at angles.

As general rule for LM screws, cranial angulation helps to reduce inferior facet joint violation. The lower the entry point is in the LM, the more cranial must be the screw trajectory to avoid facet violation[44]. At C7 due to the peculiar anatomy of the LM, screw trajectory must be more oblique than in other subaxial vertebrae. Presurgical knowledge of vertebral artery position is of critical importance to avoid unexpected vascular damage; at C7 level, the vertebral artery usually runs anterior to the LM thus being exposed to damage in case of bicortical LM screws.

In our cohort LM screws in C7 were used in only 3 cases (8.3\%) in which pedicle screws were judged to be too hazardous either due to anatomic characteristic or to pedicle involvement by the primary pathology. In all of these cases screws were placed according to Magerl's technique[25] because, in our opinion, this technique is safer and provides higher bone purchase[36].

Other techniques are available and may be used mostly as salvage techniques. C7 intralaminar screws are an effective alternative, providing a fixation biomechanically similar to LM screws[21] (Fig.4).

Trans-articular trans-facet screws have been described as a salvage technique or as an isolated facet joint fusion technique[1]. They provide provide stronger pull-out resistance because of the 4 cortical layers of bone purchase, risks are vertebral artery injury and facet fractures[1]. Two insertion techniques, proposed by Takayasu[43] and Dal Canto[9] are the most popular (Fig.4).

For Th1, as for other upper thoracic vertebrae, pedicle screws are the most stable posterior fixation technique providing a three-columns support with improved rotational strength compared to techniques of fixation involving only posterior columns[4, 35]. From $\mathrm{C} 7$ to Th2 the entry point for pedicle screws becomes more medial and the trajectory less angulated toward the midline[29].

In our series, we routinely placed pedicle screws in Th1 and upper thoracic vertebrae with an entry point 2-3mm inferior to the junction between the superior margin of the transverse process and the lateral margin of the superior articular process (Fig. 5). At Th1 level, medial angulation is usually between $20^{\circ}$ and $25^{\circ}$ medial but the correct trajectory should always be planned on a preoperative CT. The trajectory of the pedicle screw can then be either straight forward or anatomical following the anatomic plane of the pedicle[34] (Fig.5). In our surgical series, Th1 was always instrumented with PS except for 3 cases (8.4\%) in which the vertebra was skipped because of pedicle involvement by primary pathology.

Upper thoracic instrumentation techniques other than PS mostly provide fixation only in posterior vertebral elements but can be useful alternatives. Translaminar screws may be placed with the same technique described above for C7 instrumentation providing a biomechanically effective alternative to PS in the upper thoracic region[37]. Posterior fixation in the costotransverse joint is another salvage technique option [49] (Fig.5). This technique is relatively easy and safe but the fixation provided is low[35].

Rods constructs 
The connection of cervical and thoracic screws represents a specific challenge of posterior fixation across the CTJ as both have usually different screw head sizes and alignment problems may arise secondary to the different entry points and insertion techniques. The most commonly used technique is to connect two separate rods (usually 3.2-4 mm for cervical and 5.5-6 mm for thoracic) by means of lateral connectors (or dominos) or end-to-end connectors. Lateral connectors and end-to-end connectors provide the same biomechanical stiffness[48]. A more recent option are transitional dual-diameter rods. These rods present two different parts of different diameters designed to connect cervical and thoracic screws with a single bar[30]. Different diameters rods with lateral connectors are usually easier to implant because cervical and thoracic screw heads are frequently not perfectly in line.

Godzik et al.[18] found a small evidence that lateral connectors constructs provide lower biomechanical stability compared to continuous rods. Eleraky et al. [14] conversely found no differences between lateral connectors and single rod constructs. Significant differences in biomechanical stability between lateral connectors constructs and single diameter rods, whether small rods or dual diameter rods still need to be clarified. At present, there are no biomechanical studies that compared lateral connectors constructs to transitional dual diameter rods. Yang et al.[50] in an in vivo retrospective study found no differences in pseudoarthrosis rates between single diameter small rods $(3.2$ and $3.5 \mathrm{~mm})$ and mixed constructs. In the same study, transitional constructs were however associated with longer operative time and higher intraoperative blood loss.

We believe that the use of transitional dual diameter rods is the more elegant and probably the most effective technique even if this remains to be scientifically demonstrated. We used single diameter rods in 22 cases $(61.1 \%)$, most of these were small rods from a cervical set used because patients required minimal extension of the construct in the thoracic spine.

\section{Ending at $C 7$ or extend to Th1?}

While for thoracic constructs the choice to stop at Th1 or Th2 as upper instrumented vertebra[10] is generally accepted, the need for crossing the CTJ in posterior cervical constructs is still debated. At today there are only few published studies that may guide surgeons in this decision making. A hypothesized protective effect of the extension of the construct across the CTJ is thought to rely on a more rigidity provided by inclusion of the thoracic spine. Conversely, a construct ending at C7 make the involved cervical segments act as a single column leaning over the rigid thoracic spine with only a single interposed disc, thus subjected to significant mechanical stress that may result in early disc degeneration[24]. In a biomechanical study Cheng et al.[7] reported that in posterior cervical instrumentations, the intradiscal pressure of the lower adjacent disc was significantly lower for instrumentations that crossed the CTJ. The published 'in vivo' studies however provide contrasting evidences. Articles by Schroeder et al.[41], Ibaseta et al.[24] and Fayed et al.[15] found that posterior cervical constructs ending at C7, have increased risks of adjacent segment disease, while Huang et al.[22] and Lee et al.[32] found no significant increase in adjacent segment disease when stopping the construct at C7. At the same time, instrumentations that cross the CTJ have been reported to be associated with increased operative times and intraoperative blood loss[15, 22].

On the basis of the available evidences, we think that the extent of instrumentation should be tailored to the individual patient. For instance, a young patient with long life expectancy may have a higher risk of developing ASD and reasonably has a low risk of complications secondary to longer operative times and increased blood loss thus, for this kind of patients the inclusion of CTJ may be indicated. On the other hand, an elderly patient may not have enough time (intended as life expectancy) to develop an ASD but will likelihood suffer complications from prolonged duration of surgery, therefore not extending the construct below C7 may be a good choice.

\section{Spinal navigation}

Since its introduction, spinal navigation has been increasingly used in vertebral instrumentation, particularly for PS placement. Screw placement has been historically guided by anatomical landmarks, 2D-Fluoroscopy was later developed in order to increase safety and accuracy[46]. 3D-Nav techniques have been subsequently developed increasing precision of the navigation. CT guided navigation (CT-Nav) or imageless navigation guided by intraoperative 3D C-Arm acquisition (3D-Fluoronav) are the most widely used navigation techniques[46]. Recently 3D-printed guides, made from a preoperative low-dose CT scan have been introduced with the aim of accuracy's improvement and radiations' reduction[6]. Both CT-Nav and 3D-Fluoronav have shown superiority compared to 2DFluoroscopy in terms of pedicle screw accuracy with 3D-Fluoronav that seem superior to CT-Nav[12, 45]. It is of note that superiority of 3D navigation techniques is more relevant in presence of vertebral deformity[45].

The lower cervical and upper thoracic spine represent a challenging zone for conventional intraoperative fluoroscopic visualization, because they are frequently obscured by shoulders[26]. Thus, especially at the CTJ, navigation is a useful tool that helps surgeons increase safety of instrumentation. Several papers have reported the high levels of accuracy provided by CT navigated pedicle screws placement at the CTJ[38, 40].

Our surgical cohort allows to compare between methods almost in equal proportions (CT-Nav, 3D-Fluoronav and 2D-Fluoroscopy). The limited sample size and our still growing experience with 3D navigation techniques due to their relative recent standardization, probably explain the non-superiority of one technique above the other. As mentioned before, we have found a small but significant superiority of 2D-Nav and 3D-Fluoronav compared to CT-Nav when comparing optimal screw placement (GR: A) and non-optimal screw placement (GR:B+C+D+E) (Tab.4). This might be explained by our relative lack of experience in the use of O-Arm that may lead to higher rates of minimal cortical violation during screw placement. We have not placed PS in complete freehand technique without any intraoperative imaging assistance. We tend to strongly discourage this technique especially in a difficult anatomical region as the CTJ because it carries unnecessary risks that can no longer be justified in the present times. However, knowledge of anatomical landmarks and free-hand techniques are still mandatory and spine surgeons should not attempt procedures with the aid of navigation without being able to perform the same procedure without navigation.

\section{Limitations}


Our study carries the limitations of a retrospective observational surgical cohort study.

Despite our results are in line with what reported in literature, the small sample might have prevented us to find statistically significant differences between subgroups.

\section{Conclusions}

Posterior instrumentation of the CTJ is a technically demanding procedure that needs precise knowledge of the individual anatomy and its modifications caused by the underlying disease. A precise surgical planning based on primary pathology extension, patients' specific anatomy and surgeons' skills is the key for a successful treatment. Whenever safely possible, PS should be the first option for both C7 and Th1 instrumentation, but other effective fixation techniques are available when PS cannot be placed.

Different rods constructs are available although significant differences in biomechanical stability still need to be clarified.

2D Fluoroscopy guidance, remains a valuable option that can be used when 3D navigation is not available.

With correct knowledge of the available techniques, proper technical skills and precise surgical planning, posterior instrumentation of the CTJ is a safe and effective procedure.

\section{Declarations}

Funding. The authors declare that they received no financial support for this work.

Conflicts of interest/Competing interests. The authors declare that they have no conflicts of interest and no competing interests to disclosure.

Ethics approval. This study has been approved by the local ethics committee, Geneva CCER (IRB approval N²020-01185).

Consent to participate. Not applicable.

Consent for publication. Formal patient consent is not required for our paper. No data from which individual can be identified are present.

Availability of data and material. All data are available upon specific request addressed to the corresponding author.

Code availability. Not applicable.

Authors' contributions. Enrico Tessitore and Alberto Balestrino conceived the study. Alberto Balestrino and Renato Gondar drafted the manuscript; Alberto Balestrino, Gianpaolo Jannelli, Renato Gondar and Enrico Tessitore reviewed the literature. Alberto Balestrino and Gianpaolo Jannelli have given substantial contributions to acquisition, analysis and interpretation of the data. All authors have participated to drafting the manuscript, Enrico Tessitore, Alberto Balestrino, Renato Gondar and Gianluigi Zona revised it critically. All authors read and approved the final version of the manuscript.

\section{ACKNOWLEDGMENTS}

The authors would like to express their grateful thank to Alberto Bongiorno for the photographs used to describe the different instrumentation techniques.

\section{References}

1. Aydogan M, Enercan M, Hamzaoglu A, Alanay A (2012) Reconstruction of the subaxial cervical spine using lateral mass and facet screw instrumentation. Spine (Phila Pa 1976) 37:E335-41. doi: 10.1097/BRS.0b013e31824442eb

2. Bayoumi AB, Efe IE, Berk S, Kasper EM, Toktas ZO, Konya D (2018) Posterior Rigid Instrumentation of C7: Surgical Considerations and Biomechanics at the Cervicothoracic Junction. A Review of the Literature. World Neurosurg 111:216-226. doi: 10.1016/j.wneu.2017.12.026

3. Bledsoe JM, Fenton D, Fogelson JL, Nottmeier EW (2009) Accuracy of upper thoracic pedicle screw placement using three-dimensional image guidance. Spine J 9:817-21. doi: 10.1016/j.spinee.2009.06.014

4. Braga BP, Morais JV de, Vilela MD (2010) Free-hand placement of high thoracic pedicle screws with the aid of fluoroscopy: evaluation of positioning by CT scans in a four-year consecutive series. Arq Neuropsiquiatr 68:390-395. doi: 10.1590/s0004-282x2010000300012

5. Bueff HU, Lotz JC, Colliou OK, Khapchik V, Ashford F, Hu SS, Bozic K, Bradford DS (1995) Instrumentation of the cervicothoracic junction after destabilization. Spine (Phila Pa 1976) 20:1789-92. doi: 10.1097/00007632-199508150-00007

6. Cecchinato R, Berjano P, Zerbi A, Damilano M, Redaelli A, Lamartina C (2019) Pedicle screw insertion with patient-specific 3D-printed guides based on low-dose CT scan is more accurate than free-hand technique in spine deformity patients: a prospective, randomized clinical trial. Eur Spine J 28:17121723. doi: $10.1007 / \mathrm{s} 00586-019-05978-3$

7. Cheng I, Sundberg EB, lezza A, Lindsey DP, Riew KD (2015) Biomechanical Determination of Distal Level for Fusions across the Cervicothoracic Junction. Glob Spine J 5:282-286. doi: 10.1055/s-0035-1546418

8. Clifton W, Louie C, Williams DB, Damon A, Dove C, Pichelmann M (2019) Safety and Accuracy of the Freehand Placement of C7 Pedicle Screws in Cervical and Cervicothoracic Constructs. Cureus. doi: 10.7759/cureus.5304 
9. DalCanto RA, Lieberman I, Inceoglu S, Kayanja M, Ferrara L (2005) Biomechanical comparison of transarticular facet screws to lateral mass plates in two-level instrumentations of the cervical spine. Spine (Phila Pa 1976) 30:897-2. doi: 10.1097/01.brs.0000158937.64577.25

10. Daniels AH, Reid DBC, Durand WM, Hamilton DK, Passias PG, Kim HJ, Protopsaltis TS, Lafage V, Smith JS, Shaffrey Cl, Gupta M, Klineberg E, Schwab F, Burton D, Bess S, Ames CP, Hart RA (2020) Upper-thoracic versus lower-thoracic upper instrumented vertebra in adult spinal deformity patients undergoing fusion to the pelvis: Surgical decision-making and patient outcomes. J Neurosurg Spine 32:600-606. doi: 10.3171/2019.9.SPINE19557

11. Desai S, Sethi A, Ninh CC, Bartol S, Vaidya R (2010) Pedicle screw fixation of the C7 vertebra using an anteroposterior fluoroscopic imaging technique. Eur Spine J 19:1953-9. doi: 10.1007/s00586-010-1513-8

12. Du JP, Wang DH, Zhang J, Fan Y, Wu QN, Hao DJ (2018) Accuracy of Pedicle Screw Insertion Among 3 Image-Guided Navigation Systems: Systematic Review and Meta-Analysis. World Neurosurg. 109:24-30

13. Dunlap BJ, Karaikovic EE, Park H-S, Sokolowski MJ, Zhang L-Q (2010) Load sharing properties of cervical pedicle screw-rod constructs versus lateral mass screw-rod constructs. Eur Spine J 19:803-8. doi: 10.1007/s00586-010-1278-0

14. Eleraky M, Setzer M, Baaj AA, Papanastassiou I, Conrad BP, Vrionis FD (2010) Biomechanical comparison of posterior cervicothoracic instrumentation techniques after one-level laminectomy and facetectomy. J Neurosurg Spine 13:622-9. doi: 10.3171/2010.5.SPINE09848

15. Fayed I, Toscano DT, Triano MJ, Makariou E, Lee C, Spitz SM, Anaizi AN, Nair MN, Sandhu FA, Voyadzis J-M (2020) Crossing the Cervicothoracic Junction During Posterior Cervical Decompression and Fusion: Is It Necessary? Neurosurgery 86:544-550. doi: 10.1093/neuros/nyaa078

16. Fernandes Joaquim A, Mudo ML, Tan LA, Riew KD Posterior Subaxial Cervical Spine Screw Fixation: A Review of Techniques. doi: $10.1177 / 2192568218759940$

17. Gertzbein S, Robbins S (1990) Accuracy of pedicular screw placement in vivo. Spine (Phila Pa 1976) 15:11-14. doi: 10.1097/00007632-19900100000004

18. Godzik J, Dalton JF, Martinez-del-Campo E, Newcomb AGUS, Dominguez F, Reyes PM, Theodore N, Kelly BP, Crawford NR (2019) Biomechanical Evaluation of Cervicothoracic Junction Fusion Constructs. World Neurosurg 124:e139-e146. doi: 10.1016/j.wneu.2018.12.040

19. Heller JG, Carlson GD, Abitbol JJ, Garfin SR (1991) Anatomic comparison of the Roy-Camille and Magerl techniques for screw placement in the lower cervical spine. Spine (Phila Pa 1976) 16:S552-S557. doi: 10.1097/00007632-199110001-00020

20. Hilibrand AS, Robbins M (2004) Adjacent segment degeneration and adjacent segment disease: The consequences of spinal fusion? Spine J 4:S190S194. doi: 10.1016/j.spinee.2004.07.007

21. Hong JT, Tomoyuki T, Jain A, Orías AAE, Inoue N, An HS (2017) Which salvage fixation technique is best for the failed initial screw fixation at the cervicothoracic junction? A biomechanical comparison study. Eur Spine J 26:2417-2424. doi: 10.1007/s00586-017-5239-8

22. Huang KT, Harary M, Abd-El-Barr MM, Chi JH (2019) Crossing the Cervicothoracic Junction in Posterior Cervical Decompression and Fusion: A Cohort Analysis. World Neurosurg 131:e514-e520. doi: 10.1016/j.wneu.2019.07.219

23. Hyun S-J, Lee BH, Park J-H, Kim K-J, Jahng T-A, Kim H-J (2017) Proximal Junctional Kyphosis and Proximal Junctional Failure Following Adult Spinal Deformity Surgery. Korean J Spine 14:126-132. doi: 10.14245/kjs.2017.14.4.126

24. Ibaseta A, Rahman R, Andrade NS, Uzosike AC, Byrapogu VK, Ramji AF, Skolasky RL, Reidler JS, Kebaish KM, Riley LH, Sciubba DM, Cohen DB, Neuman BJ (2019) Crossing the Cervicothoracic Junction in Cervical Arthrodesis Results in Lower Rates of Adjacent Segment Disease without Affecting Operative Risks or Patient-Reported Outcomes. Clin Spine Surg 32:377-381. doi: 10.1097/BSD.0000000000000897

25. Jeanneret B, Magerl F, Ward EH, Ward JC (1991) Posterior stabilization of the cervical spine with hook plates. Spine (Phila Pa 1976) 16:S56-63. doi: $10.1097 / 00007632-199103001-00010$

26. Jenkins AL, Singh H, Meyer SA, Hecht AC (2009) Novel fluoroscopic technique for localization at cervicothoracic levels. J Spinal Disord Tech 22:615618. doi: 10.1097/BSD.0b013e31818da7ce

27. Kaya RA, Türkmenoğlu ON, Koç ÖN, Genç HA, Çavuçoğlu H, Ziyal IM, Aydin Y (2006) A perspective for the selection of surgical approaches in patients with upper thoracic and cervicothoracic junction instabilities. Surg Neurol 65:454-463. doi: 10.1016/j.surneu.2005.08.017

28. Kim HJ, Lenke LG, Shaffrey Cl, Van Alstyne EM, Skelly AC (2012) Proximal junctional kyphosis as a distinct form of adjacent segment pathology after spinal deformity surgery: A systematic review. Spine (Phila. Pa. 1976). 37

29. Kreshak JL, Kim DH, Lindsey DP, Kam AC, Panjabi MM, Yerby SA (2002) Posterior stabilization at the cervicothoracic junction: A biomechanical study. Spine (Phila Pa 1976) 27:2763-2770. doi: 10.1097/00007632-200212150-00005

30. Kulkarni AG, Dhruv AN, Bassi AJ (2015) Posterior Cervicothoracic Instrumentation, Testing the Clinical Efficacy of Tapered Rods (Dual-Diameter Rods). J Spinal Disord Tech 28:382-388. doi: 10.1097/bsd.0000000000000133

31. Kumar S, van Popta D, Rodrigues-Pinto R, Stephenson J, Mohammad S, Siddique I, Verma RR (2015) Risk factors for wound infection in surgery for spinal metastasis. Eur Spine J 24:528-532. doi: 10.1007/s00586-013-3127-4

32. Lee DH, Cho JH, Jung J II, Baik JM, Jun DS, Hwang CJ, Lee CS (2019) Does stopping at C7 in long posterior cervical fusion accelerate the symptomatic breakdown of cervicothoracic junction? PLoS One 14:1-10. doi: 10.1371/journal.pone.0217792

33. Lee DH, Lee SW, Kang SJ, Hwang CJ, Kim NH, Bae JY, Kim YT, Lee CS, Daniel Riew K (2011) Optimal entry points and trajectories for cervical pedicle screw placement into subaxial cervical vertebrae. Eur Spine J 20:905-911. doi: 10.1007/s00586-010-1655-8

34. Lehman RA, Polly DW, Kuklo TR, Cunningham B, Kirk KL, Belmont PJ (2003) Straight-forward Versus anatomic trajectory technique of thoracic pedicle screw fixation: A biomechanical analysis. In: Spine. pp 2058-2065 
35. Little AS, Brasiliense LBC, Lazaro BCR, Reyes PM, Dickman CA, Crawford NR (2010) Biomechanical Comparison of Costotransverse Process Screw Fixation and Pedicle Screw Fixation of the Upper Thoracic Spine. Oper Neurosurg 66:ons178-ons182. doi: 10.1227/01.neu.0000350869.35779.05

36. Mazel CR, Saillant G (1987) 3 . 1. Treatment of Cervical Spine Injuries by a Posterior Osteosynthesis I . Anatomy. 3-4

37. McGirt MJ, Sutter EG, Xu R, Sciubba DM, Wolinsky J-P, Witham TF, Gokaslan ZL, Bydon A (2009) Biomechanical comparison of translaminar versus pedicle screws at T1 and T2 in long subaxial cervical constructs. Neurosurgery 65:167-72; discussion 172. doi: 10.1227/01.NEU.0000345642.50726.A3

38. Rienmüller A, Buchmann N, Kirschke JS, Meyer EL, Gempt J, Lehmberg J, Meyer B, Ryang YM (2017) Accuracy of CT-navigated pedicle screw positioning in the cervical and upper thoracic region with and without prior anterior surgery and ventral plating. Bone Jt J 99B:1373-1380. doi: 10.1302/0301620X.99B10.BJJ-2016-1283.R1

39. Schatlo B, Molliqaj G, Cuvinciuc V, Kotowski M, Schaller K, Tessitore E (2014) Safety and accuracy of robot-assisted versus fluoroscopy-guided pedicle screw insertion for degenerative diseases of the lumbar spine: A matched cohort comparison - Clinical article. J Neurosurg Spine 20:636-643. doi: 10.3171/2014.3.SPINE13714

40. Scheufler KM, Franke J, Eckardt A, Dohmen H (2011) Accuracy of image-guided pedicle screw placement using intraoperative computed tomographybased navigation with automated referencing, part I: Cervicothoracic spine. Neurosurgery 69:782-795. doi: 10.1227/NEU.0b013e318222ae16

41. Schroeder GD, Kepler CK, Kurd MF, Mead L, Millhouse PW, Kumar P, Nicholson K, Stawicki C, Helber A, Fasciano D, Patel AA, Woods BI, Radcliff KE, Rihn JA, Greg Anderson D, Hilibrand AS, Vaccaro AR (2016) Is it necessary to extend a multilevel posterior cervical decompression and fusion to the upper thoracic Spine? Spine (Phila Pa 1976) 41:1845-1849. doi: 10.1097/BRS.0000000000001864

42. Stemper BD, Marawar S V., Yoganandan N, Shender BS, Rao RD (2008) Quantitative anatomy of subaxial cervical lateral mass: An analysis of safe screw lengths for Roy-Camille and Magerl techniques. Spine (Phila Pa 1976) 33:893-897. doi: 10.1097/BRS.0b013e31816b4666

43. Takayasu M, Hara M, Yamauchi K, Yoshida M, Yoshida J (2003) Transarticular screw fixation in the middle and lower cervical spine. Technical note. J Neurosurg 99:132-136. doi: 10.3171/spi.2003.99.1.0132

44. Tessitore E, El-Hassani Y, Schaller K (2011) How i do it: Cervical lateral mass screw fixation. Acta Neurochir (Wien) 153:1695-1699. doi: 10.1007/s00701-011-1068-4

45. Tian NF, Huang QS, Zhou P, Zhou Y, Wu RK, Lou Y, Xu HZ (2011) Pedicle screw insertion accuracy with different assisted methods: A systematic review and meta-analysis of comparative studies. Eur. Spine J. 20:846-859

46. Walker CT, Kakarla UK, Chang SW, Sonntag VKH (2019) History and advances in spinal neurosurgery. J Neurosurg Spine 31:775-785. doi: 10.3171/2019.9.SPINE181362

47. Wang VY, Chou D (2007) The cervicothoracic junction. Neurosurg Clin N Am 18:365-71. doi: 10.1016/j.nec.2007.02.012

48. Welke B, Schwarze M, Hurschler C, Nebel D, Bergmann N, Daentzer D (2018) In vitro investigation of two connector types for continuous rod construct to extend lumbar spinal instrumentation. Eur Spine J 27:1895-1904. doi: 10.1007/s00586-018-5664-3

49. Xu R, Ebraheim NA, Ou Y, Skie M, Yeasting RA (2000) Anatomic Considerations of Costotransverse Screw Placement in the Thoracic Spine

50. Yang JS, Buchowski JM, Verma V (2015) Construct type and risk factors for pseudarthrosis at the cervicothoracic junction. Spine (Phila Pa 1976) 40:E613-E617. doi: 10.1097/BRS.0000000000000868

\section{Tables}

Table 1. Patients' demographic and data regarding posterior instrumentation surgery. 


\begin{tabular}{|c|c|c|c|c|c|c|c|c|c|c|c|c|c|}
\hline$N^{0}$ & Age & Sex & Comorbidities & Etiology & $\begin{array}{l}\text { Level } \\
\text { of } \\
\text { primary } \\
\text { lesion }\end{array}$ & $\begin{array}{l}\text { UIV- } \\
\text { LIV }\end{array}$ & $\begin{array}{l}N^{\circ} \text { of } \\
\text { levels }\end{array}$ & Navigation & $\begin{array}{l}\text { Subaxial } \\
\text { cervical } \\
\text { fixation }\end{array}$ & $\begin{array}{l}\text { C7 } \\
\text { fixation }\end{array}$ & $\begin{array}{l}\text { T1 } \\
\text { fixation }\end{array}$ & $\begin{array}{l}\text { Upper } \\
\text { thoracic } \\
\text { fixation }\end{array}$ & $\begin{array}{l}\text { Rods } \\
\text { type }\end{array}$ \\
\hline 1 & 53 & $M$ & $\begin{array}{l}\text { Smoke, alcohol } \\
\text { abuse }\end{array}$ & Trauma & S-CTJ & $\begin{array}{l}\text { C5- } \\
\text { T1 }\end{array}$ & 3 & $2 \mathrm{D}$ & LM & PS & PS & PS & SR \\
\hline 2 & 23 & M & No & Trauma & CTJ-T & $\begin{array}{l}\text { C6- } \\
\text { T4 }\end{array}$ & 5 & $2 \mathrm{D}$ & LM & PS & No & PS & DC \\
\hline 3 & 44 & $\mathrm{~F}$ & No & Degenerative & S-CTJ & $\begin{array}{l}\text { C4- } \\
\text { T2 }\end{array}$ & 5 & $2 \mathrm{D}$ & LM & LM & PS & PS & SR \\
\hline 4 & 35 & $\mathrm{~F}$ & $\begin{array}{l}\text { Smoke, alcohol and } \\
\text { cocaine abuse }\end{array}$ & Trauma & $\begin{array}{l}\text { S-CTJ- } \\
T\end{array}$ & $\begin{array}{l}\text { C4- } \\
\text { T8 }\end{array}$ & 11 & $2 \mathrm{D}$ & LM & No & PS & PS & DC \\
\hline 5 & 44 & M & No & Trauma & $\begin{array}{l}\text { S-CTJ- } \\
\text { T }\end{array}$ & $\begin{array}{l}\text { C4- } \\
\text { T4 }\end{array}$ & 7 & 3D 0-arm & LM & PS & PS & PS & DC \\
\hline 6 & 42 & M & No & Trauma & S-CTJ & $\begin{array}{l}\text { C5- } \\
\text { T1 }\end{array}$ & 3 & $2 \mathrm{D}$ & LM & No & PS & No & SR \\
\hline 7 & 66 & $\mathrm{~F}$ & No & Degenerative & CTJ & $\begin{array}{l}\text { C7- } \\
\text { T1 }\end{array}$ & 1 & 3D 0-arm & No & PS & PS & No & SR \\
\hline 8 & 40 & $\mathrm{~F}$ & No & Degenerative & S-CTJ & $\begin{array}{l}\text { C3- } \\
\text { T2 }\end{array}$ & 6 & 3D 0-arm & LM & PS & PS & PS & SR \\
\hline 9 & 91 & M & No & Trauma & S-CTJ & $\begin{array}{l}\text { C5- } \\
\text { T1 }\end{array}$ & 3 & $2 \mathrm{D}$ & LM & PS & PS & No & SR \\
\hline 10 & 74 & $\mathrm{~F}$ & Hyperthyroidism & Trauma & CTJ & $\begin{array}{l}\text { C4- } \\
\text { T3 }\end{array}$ & 6 & 3D 0-arm & LM & No & PS & PS & TR \\
\hline 11 & 51 & M & No & Trauma & CTJ & $\begin{array}{l}\text { C7- } \\
\text { T1 }\end{array}$ & 1 & 3D 0-arm & No & PS & PS & No & SR \\
\hline 12 & 54 & $M$ & No & Degenerative & $S$ & $\begin{array}{l}\text { C3- } \\
\text { T1 }\end{array}$ & 5 & 3D 0-arm & LM & PS & PS & No & SR \\
\hline 13 & 77 & M & No & Trauma & S-CTJ & $\begin{array}{l}\text { C5- } \\
\text { T1 }\end{array}$ & 3 & $2 \mathrm{D}$ & LM & PS & PS & No & DC \\
\hline 14 & 77 & $\mathrm{~F}$ & Thyroid carcinoma & Tumor & $\mathrm{T}$ & $\begin{array}{l}\text { C7- } \\
\text { T4 }\end{array}$ & 4 & 3D 0-arm & No & PS & PS & PS & SR \\
\hline 15 & 18 & $M$ & $\begin{array}{l}\text { Neurofibromatosis } \\
\text { type } 1\end{array}$ & Tumor & CTJ & $\begin{array}{l}\text { C6- } \\
\text { T1 }\end{array}$ & 2 & $2 D$ & LM & No & PS & No & SR \\
\hline 16 & 53 & $M$ & $\begin{array}{l}\text { Type } 1 \text { diabete, } \\
\text { alcohol abuse }\end{array}$ & Trauma & CTJ & $\begin{array}{l}\text { C6- } \\
\text { T1 }\end{array}$ & 2 & $2 \mathrm{D}$ & LM & No & PS & No & SR \\
\hline 17 & 51 & $\mathrm{~F}$ & Obesity & Degenerative & CTJ & $\begin{array}{l}\text { C3- } \\
\text { T3 }\end{array}$ & 7 & 3D 0-arm & LM & No & PS & PS & SR \\
\hline 18 & 65 & M & No & Trauma & CTJ & $\begin{array}{l}\text { C6- } \\
\text { T1 }\end{array}$ & 2 & $2 \mathrm{D}$ & LM & PS & PS & No & SR \\
\hline 19 & 78 & M & Type 2 diabete & Tumor & CTJ & $\begin{array}{l}\text { C7- } \\
\text { T2 }\end{array}$ & 2 & 3D 0-arm & No & PS & No & PS & SR \\
\hline 20 & 62 & $\mathrm{~F}$ & No & Tumor & S-CTJ & $\begin{array}{l}\mathrm{C} 4- \\
\mathrm{T} 2\end{array}$ & 5 & $2 \mathrm{D}$ & LM & LM & PS & PS & SR \\
\hline 21 & 64 & $\mathrm{~F}$ & $\begin{array}{l}\text { Obesity, renal and } \\
\text { hepatic insufficiency, } \\
\text { HIV+ }\end{array}$ & Tumor & $\mathrm{T}$ & $\begin{array}{l}\text { C7- } \\
\text { T4 }\end{array}$ & 4 & 3D C-arm & No & PS & PS & PS & SR \\
\hline 22 & 74 & M & Parkinson disease & Degenerative & CTJ & $\begin{array}{l}\text { C5- } \\
\text { T3 }\end{array}$ & 5 & 3D 0-arm & PS & PS & PS & PS & TR \\
\hline 23 & 64 & M & Type 2 diabete & Degenerative & S-CTJ & $\begin{array}{l}\text { C3- } \\
\text { T2 }\end{array}$ & 6 & 3D C-arm & LM & No & PS & PS & TR \\
\hline 24 & 19 & M & No & Trauma & CTJ & $\begin{array}{l}\text { C7- } \\
\text { T1 }\end{array}$ & 1 & $2 \mathrm{D}$ & No & PS & PS & No & SR \\
\hline 25 & 64 & $M$ & No & Degenerative & S-CTJ & $\begin{array}{l}\text { C4- } \\
\text { T1 }\end{array}$ & 4 & 3D C-arm & LM & PS & PS & No & SR \\
\hline 26 & 59 & M & $\begin{array}{l}\text { Cowden syndrome, } \\
\text { C2-3 arterio-venous } \\
\text { malformation }\end{array}$ & Degenerative & S-CTJ & $\begin{array}{l}\text { C5- } \\
\text { T1 }\end{array}$ & 3 & 3D C-arm & LM & PS & PS & No & TR \\
\hline 27 & 83 & M & $\begin{array}{l}\text { Anticoagulation for } \\
\text { atrial fibrillation }\end{array}$ & Trauma & CTJ & $\begin{array}{l}\text { C5- } \\
\text { T2 }\end{array}$ & 4 & 3D C-arm & LM & PS & PS & PS & TR \\
\hline
\end{tabular}




\begin{tabular}{|c|c|c|c|c|c|c|c|c|c|c|c|c|c|}
\hline 28 & 62 & M & No & Degenerative & S-CTJ & $\begin{array}{l}\text { C3- } \\
\text { T1 }\end{array}$ & 5 & 3D C-arm & LM & No & PS & PS & TR \\
\hline 29 & 53 & $\mathrm{~F}$ & $\begin{array}{l}\text { Chronic obstructive } \\
\text { pulmonary disease }\end{array}$ & Degenerative & $S$ & $\begin{array}{l}\text { C4- } \\
\text { T1 }\end{array}$ & 4 & 3D C-arm & LM & PS & PS & No & TR \\
\hline 30 & 55 & $\mathrm{~F}$ & No & Degenerative & S & $\begin{array}{l}\mathrm{C} 2- \\
\mathrm{T} 2\end{array}$ & 7 & 3D C-arm & LM & No & PS & PS & $\begin{array}{l}\text { TR- } \\
\text { DC }\end{array}$ \\
\hline 31 & 52 & M & No & Degenerative & S-CTJ & $\begin{array}{l}\text { C5- } \\
\text { T1 }\end{array}$ & 3 & 3D C-arm & LM & PS & PS & No & SR \\
\hline 32 & 73 & M & $\begin{array}{l}\text { Ankylosing } \\
\text { spondylitis }\end{array}$ & Trauma & S-CTJ & $\begin{array}{l}\text { C4- } \\
\text { T2 }\end{array}$ & 5 & $2 \mathrm{D}$ & LM & PS & PS & PS & $\mathrm{DC}$ \\
\hline 33 & 74 & $\mathrm{~F}$ & Thyroid carcinoma & Tumor & CTJ-T & $\begin{array}{l}\text { C5- } \\
\text { T5 }\end{array}$ & 7 & 3D C-arm & LM & LM & No & PS & TR \\
\hline 34 & 48 & $\mathrm{~F}$ & Hyperparathyroidism & Degenerative & S-CTJ & $\begin{array}{l}\text { C5- } \\
\text { T1 }\end{array}$ & 3 & 3D C-arm & LM & No & PS & No & SR \\
\hline 35 & 60 & $\mathrm{~F}$ & $\begin{array}{l}\text { Hepatocellular } \\
\text { carcinoma }\end{array}$ & Tumor & CTJ & $\begin{array}{l}\text { C7- } \\
\text { T2 }\end{array}$ & 2 & 3D C-arm & No & PS & PS & PS & SR \\
\hline 36 & 54 & $\mathrm{~F}$ & Alcohol abuse & Trauma & S-CTJ & $\begin{array}{l}\text { C4- } \\
\text { T1 }\end{array}$ & 4 & 3D 0-arm & LM & PS & PS & No & SR \\
\hline
\end{tabular}

S: subaxial; CTJ: cervico-thoracic junction; T: thoracic; M: myelopathy; I: instability; R: radiculopathy; UIV: upper instrumented vertebra, LIV: Iower instrumented vertebra, LM: lateral mass screws, PS: pedicle screws, SR: Small rods, DC: domino connectors, TR: transitional dual diameter rods.

Table 2. Pedicle screw placement accuracy according to Gerstzbein-Robbins classification.

\begin{tabular}{|llll|}
\hline GR grade & C7 & Th1 & C7 and Th1 \\
\hline A & $26(55.5 \%)$ & $45(71.4 \%)$ & $71(64.5 \%)$ \\
B & $13(27.7 \%)$ & $14(22.2 \%)$ & $27(24.5 \%)$ \\
\hline C & $4(8.4 \%)$ & $1(1.6 \%)$ & $5(4.5 \%)$ \\
\hline D & $1(2.1 \%)$ & 0 & $1(0.9 \%)$ \\
E & $3(6.3 \%)$ & $3(4.8 \%)$ & $6(5.4 \%)$ \\
\hline Total & 47 & 63 & 110 \\
\hline
\end{tabular}

GR: Gerstzbein-Robbins.

Table 3. Analysis of pedicle screw placement accuracy between different navigation techniques.

\begin{tabular}{|llll|}
\hline GR grade & $2 D$ Navigation $(n=36)$ & 3 N Navigation $(n=70)$ & \\
A & 27 & 43 & $\mathrm{p}=0,1971$ \\
B+C+D+E & 9 & 27 & \\
A+B & 34 & 62 & $\mathrm{p}=0,4888$ \\
C+D+E & 2 & 8 & \\
\hline
\end{tabular}

GR: Gerstzbein-Robbins.

Table 4. Subgroup analysis of pedicle screw placement accuracy between different navigation techniques.

\begin{tabular}{|lllll|}
\hline GR grade & 2 D-Nav & CT-Nav & 3D-Fluoronav & \\
A & 27 & 18 & 25 & $\mathrm{p}<0,05$ \\
\hline B+C+D+E & 9 & 19 & 8 & \\
& & & & \\
A+B & 34 & 31 & 31 & $\mathrm{p}=0,2159$ \\
$\mathrm{C}+\mathrm{D}+\mathrm{E}$ & 2 & 6 & 2 & \\
\hline
\end{tabular}


GR: Gerstzbein-Robbins. 2D-Nav: intraoperative 2D fluoroscopy; CT-Nav: 3D intraoperative navigation with O-Arm acquisition; 3D-Fluoronav: 3D intraoperative navigation with 3D fluoroscopy acquisition.

\section{Figures}
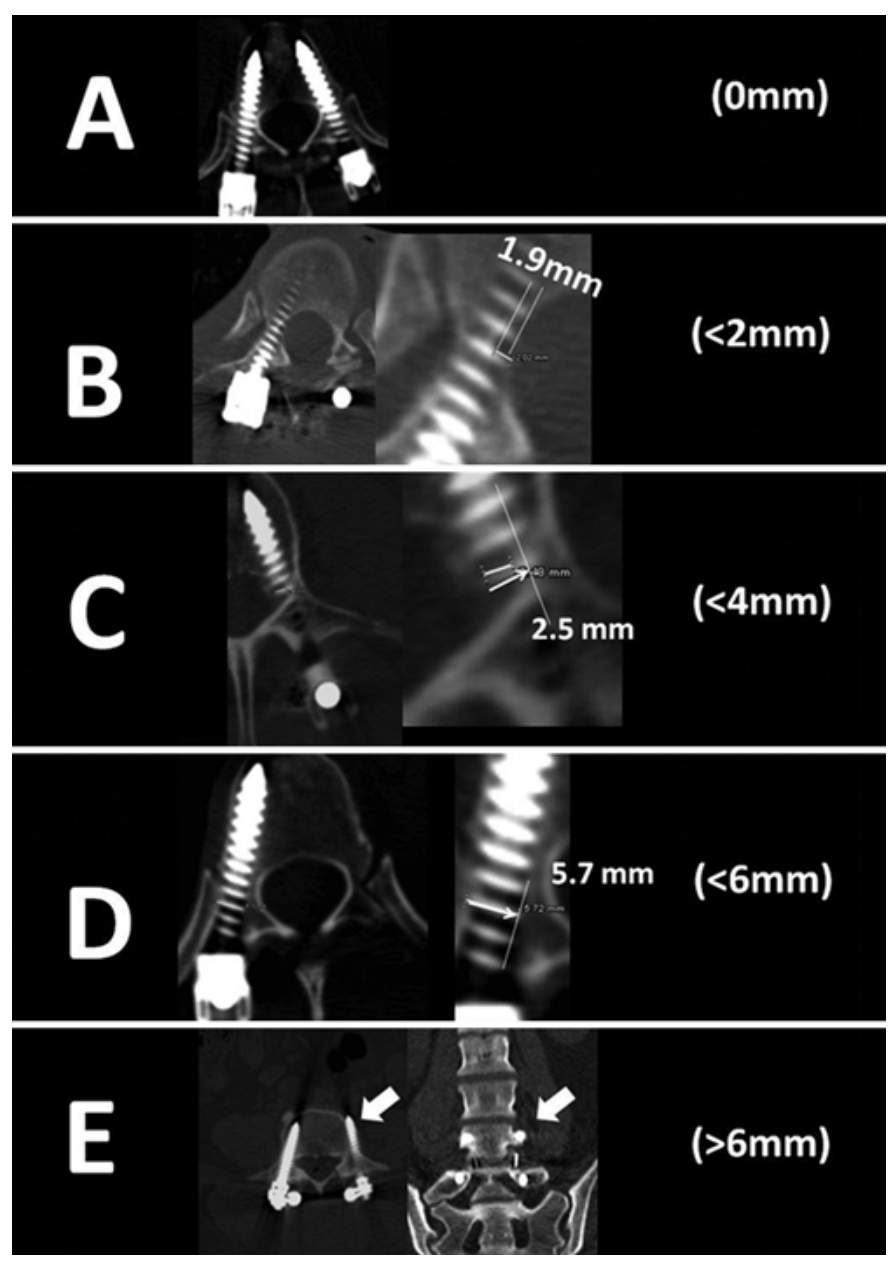

Figure 1

Gertzbein and Robbins Classification of pedicle screw placement accuracy. Grade is defined by the amount of pedicle's cortical breach[39] 


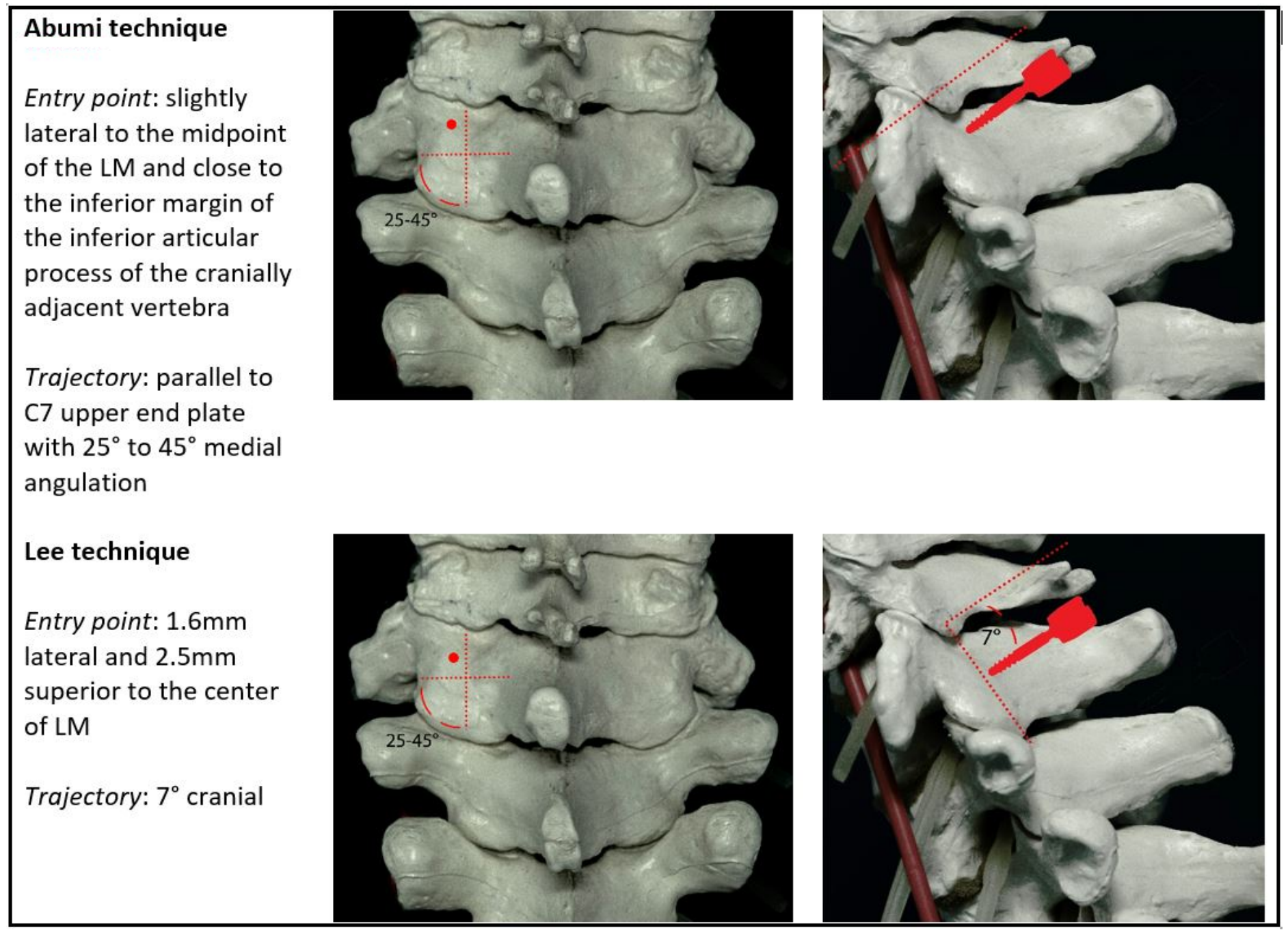

Figure 2

Techniques for pedicle screw placement on C7. LM: Lateral Mass 


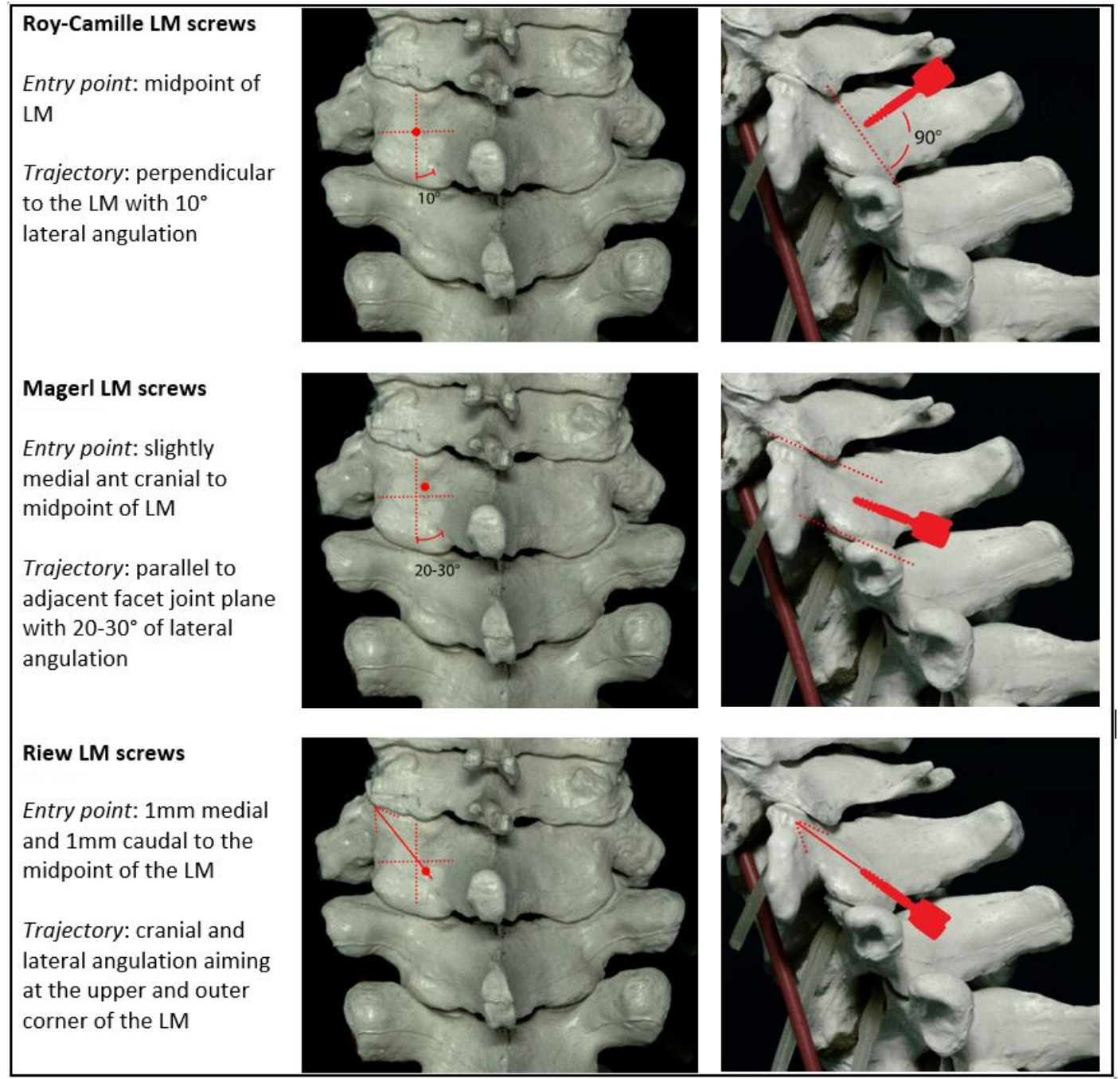

\section{Figure 3}

Lateral mass screw insertion techniques. LM: Lateral Mass 
Intralaminar screws -

Hong technique

Entry point: at the spinolaminar junction,

on one side at the

caudal aspect and on

the contralateral side at

the rostral aspect

Trajectory: inside the

contralateral lamina

Trans-articular trans-

facet screws - Takayasu

technique

Entry point: on the

midline of the articular

mass in the junction

between the superior

third and the median

third
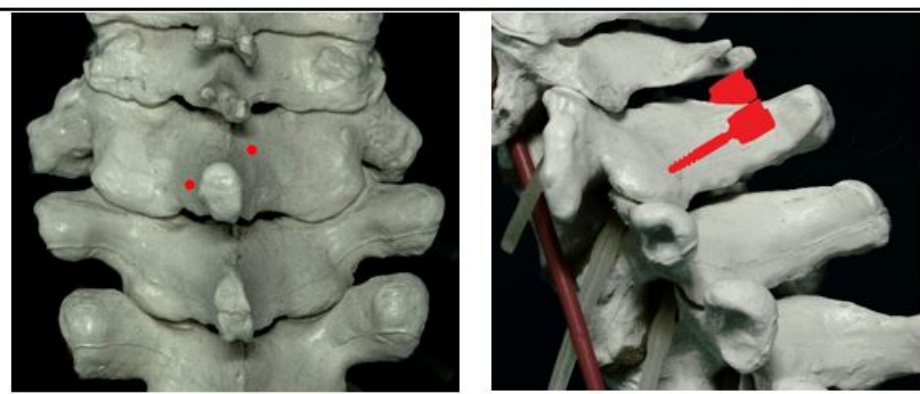

Trajectory: purely

sagittal with a $60^{\circ}$ to

$80^{\circ}$ caudal angulation

Trans-articular trans-

facet screws - DalCanto

technique

Entry point: $2 \mathrm{~mm}$

inferior to the midpoint

of the LM

Trajectory: $40^{\circ}$ caudal

and $20^{\circ}$ lateral

angulation
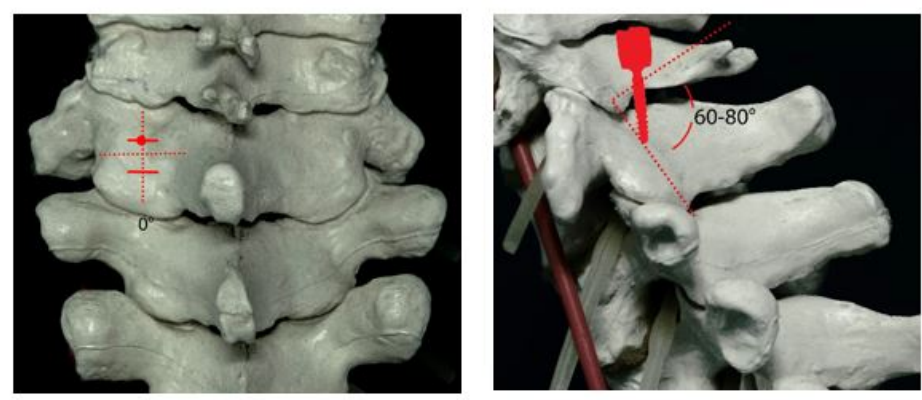

\section{Figure 4}

Other techniques for posterior C7 instrumentation. LM: Lateral Mass 
Th1 Pedicle screws

Entry point: $2-3 \mathrm{~mm}$ inferior to the junction between the superior margin of the transverse process and the lateral margin of the superior articular process

Trajectory: $20-25^{\circ}$ medial angulation with anatomical (a) or straight forward (b) trajectory

\section{Costo-transverse joint fixation technique}

Entry point: midpoint of clubbed extremity of the transverse process

Trajectory: $0^{\circ}$ sagittal and cranial orientation under direct visualization of the costotransverse articulation pointing at the upper portion of the rib
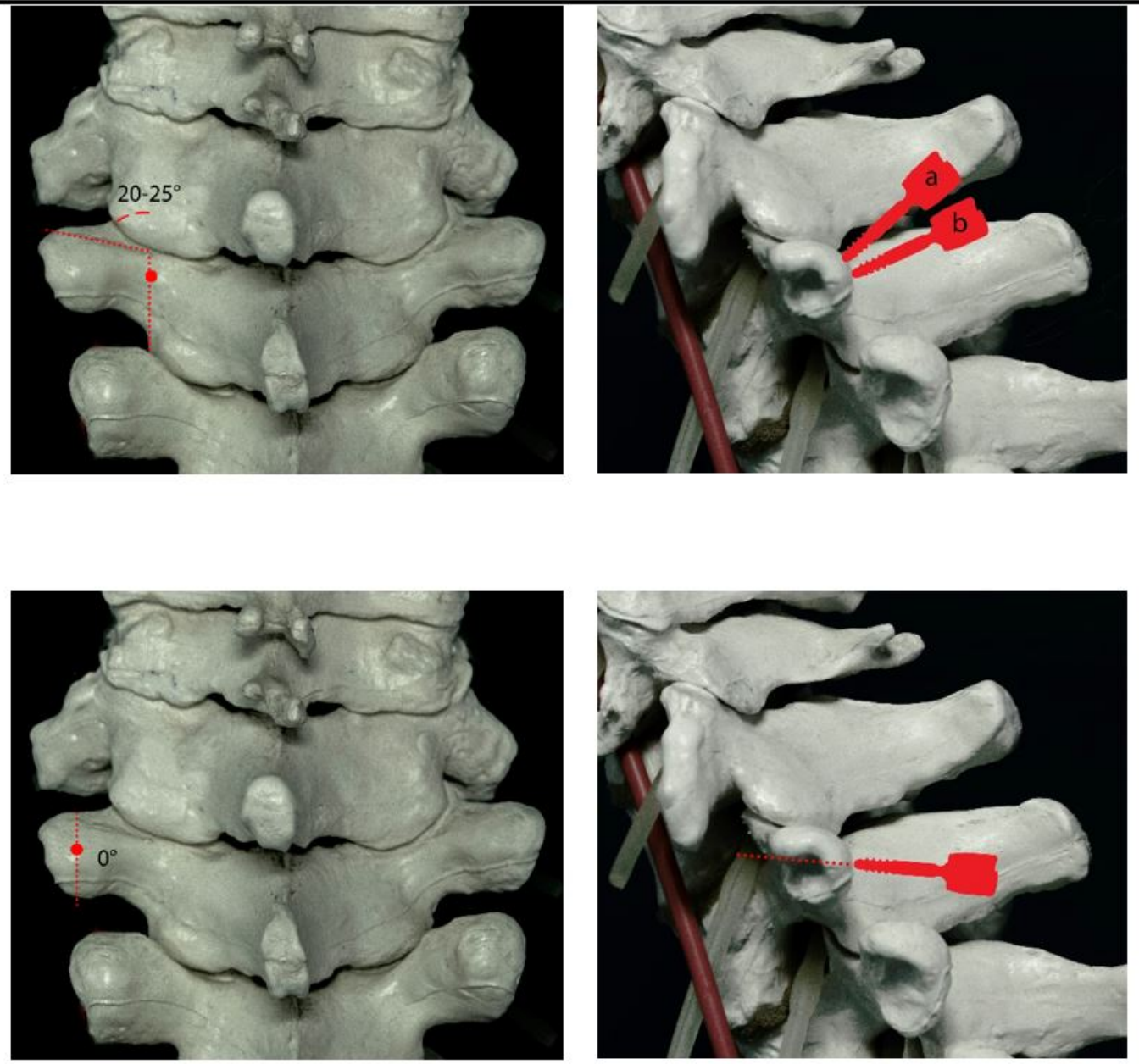

Figure 5

Techniques for posterior instrumentation of Th1 